\title{
Principales aspectos de la nodulación y fijación biológica de nitrógeno en Fabáceas
}

\section{Main aspects of the nodulation and biological fixation of nitrogen in Fabáceas}

\author{
Luciana Bianco ${ }^{1,2 *}$
}

\section{RESUMEN}

Se han realizado numerosas investigaciones sobre la nodulación, principalmente en leguminosas de importancia agronómica. No obstante, son muchas las especies nativas que solo se han caracterizado superficialmente y miles permanecen aún sin haber sido exploradas. El estudio sobre la nodulación en las leguminosas nativas proporcionará conocimientos fundamentales para la conservación y utilización de aquellas especies que se adaptan a vivir en condiciones ambientales adversas. Por ese motivo, los objetivos de esta revisión son: a) describir los mecanismos de infección -hasta ahora conocidos- de los rizobios asociados a las Fabáceas; b) analizar los trabajos de investigación más importantes reportados hasta la fecha sobre la morfología y estructura de los nódulos, y c) sintetizar los avances más significativos sobre la nodulación en las tres subfamilias de Fabáceas. Se concluye que hasta la fecha se conocen tres mecanismos de infección por parte de los rizobios: I) los hilos de infección en los pelos radicales que sucede en géneros como Acacia, Mimosa y Prosopis, pertenecientes a la subfamilia Mimosoideae; así como en Lotus, Medicago y Robinia, pertenecientes a la subfamilia Papilionoideae; II) el mecanismo de crack entry que ocurre en las leguminosas de la tribu Dalbergieae, y III) la infección directa a través de la epidermis de la raíz que es característica de la tribu Genisteae. Como resultado de la infección bacteriana se forman distintos tipos morfológicos de nódulos. Con respecto a la estructura, están constituidos por tres tipos de tejidos que poseen una función específica en la fijación de nitrógeno. En especies sujetas a condiciones desfavorables se observan modificaciones en la estructura, como la formación de peridermis y lenticelas. Actualmente, la subfamilia Papilionoideae es la más estudiada en cuanto a nodulación, particularmente los géneros pertenecientes a las tribus Dalbergieae, Desmodieae, Genisteae, Loteae, Millettieae, Phaseoleae, Sophoreae y Trifolieae.

Palabras clave: leguminosas, nativas, nódulos, rizobios.

\section{ABSTRACT}

Several investigations have been carried out on nodulation mainly in legumes of agronomic importance. However, several native species still remain completely unexplored. The study of nodulating native legumes will provide key knowledge for the conservation and management of species with adaptation to harsh environmental conditions. Therefore, the purposes of this review are: a) To describe the infection mechanisms of rhizobia associated with Fabaceae known until now, b) To analyze the most important research works reported on nodule morphology and structure, c) synthesize the most significant advances on nodulation in the three sub-families of Fabaceae. It is concluded that to date three infection mechanisms by rhizobia are known: I) The infection threads in the radical hairs that occur in genera such as Acacia, Mimosa and Prosopis belonging to the Mimosoideae sub-family; as well as in Lotus, Medicago and Robinia, belonging to the Papilionoideae sub-family, II) the crack entry mechanism that occurs in legumes of the Dalbergieae tribe, and III) direct infection through the epidermis root characteristic of the Genisteae tribe. As a result of bacterial infection different morphological types of nodules are formed. Regarding the structure, they are constituted by three types of tissues that have a specific function in the nitrogen fixation. In species subjected to unfavorable conditions, changes in structure are observed, such as the formation of periderm and lenticels.

Currently, the sub-family Papilionoideae is the most studied as far as nodulation is concerned, particularly the genera belonging to the tribus Dalbergieae, Desmodieae, Genisteae, Loteae, Millettieae, Phaseoleae, Sophoreae and Trifolieae.

Keywords: Legumes, Natives, Nodules, Rhizobia.

1 Laboratorio de Morfología Vegetal, Facultad de Agronomía y Veterinaria, Universidad Nacional de Río Cuarto. Río Cuarto. Provincia de Córdoba, Argentina.

2 Instituto Nacional de Investigación en Agrobiotecnología (INIAB CONICET-UNRC). Río Cuarto, Provincia de Córdoba, Argentina.

* Autor por correspondencia: lbianco@ayv.unrc.edu.ar.

Fecha de Recepción: 3 de Diciembre, 2019.

Fecha de Aceptación: 6 Febrero, 2020. 


\section{Introducción}

La familia Fabaceae (= Leguminosae) se divide en las subfamilias Caesalpinioideae, Mimosoideae y Papilionoideae e incluye aproximadamente 750 géneros y 20.000 especies distribuidas en todo el mundo. Muchas especies de esta familia son económicamente importantes por su calidad forrajera y tienen una función trascendente en la contribución de proteínas a la dieta de los rumiantes. Asimismo, son capaces de producir una buena cantidad de biomasa y mejorar la calidad del suelo (Ampomah et al., 2012). Por otro lado, algunas leguminosas son importantes comercialmente ya que producen madera, leña, carbón y productos farmacológicos, entre otros. Algunas especies de los géneros Albizia, Erythrina e Inga también se utilizan como plantas que dan sombra en cultivos como el cacao y el café (Sprent y Parsons, 2000; Sprent, 2005). Otro aspecto relevante de esta familia es que muchas leguminosas nativas son candidatas ideales para su uso en proyectos de restauración y rehabilitación de tierras, ya que son resistentes a la sequía y mejoran la fertilidad del suelo mediante la fijación biológica de nitrógeno (FBN).

Se ha estimado que las áreas áridas y semiáridas ocupan una fracción del $45 \%$ de la superficie de la Tierra como resultado de los niveles actuales de desertificación y cambio climático (Shimel, 2010). Aunque antes no eran económicamente importantes, en las últimas tres décadas se han vuelto fundamentales para mantener y mejorar el suministro de alimentos para una creciente población mundial. Las áreas áridas se caracterizan por presentar lluvias ocasionales, sequías frecuentes, radiación solar intensa, temperaturas extremas y vientos fuertes. Todos estos factores hacen que los suelos sean pobres en materia orgánica y nutrientes (Zahran, 1999). Los fertilizantes orgánicos y/o inorgánicos a menudo se usan para aumentar la fertilidad en suelos áridos y desérticos. Debido a esto, se observó que, en dosis altas, pueden tener efectos negativos e impredecibles en el medio ambiente y contaminar el suelo, el agua y las áreas naturales. Por lo tanto, la FBN ha demostrado ser una mejor alternativa para introducir $\mathrm{N}$ (nitrógeno) naturalmente en estos ecosistemas, haciéndolos productivos y sustentables. En estas zonas se debe intentar cultivar leguminosas nativas, ya que los rizobios con los cuales se asocian se encuentran adaptados al ambiente y pueden establecer simbiosis bajo condiciones de estrés (Sprent y Gehlot, 2010).
El éxito de las leguminosas nativas se puede atribuir no solo a su capacidad para establecer simbiosis y fijar $\mathrm{N}$, sino también a otras adaptaciones como formación de micorrizas (arbusculares, ectomicorrizas o ambas), formación de "cluster roots", formación de "shovel roots" y producción de sustancias para la defensa de herbívoros (Sprent y Parsons, 2000).

Teniendo en cuenta la relevancia económica y ecológica de esta familia, los objetivos de este trabajo son: a) describir los mecanismos de infección -hasta ahora conocidos- de los rizobios asociados a las Fabáceas; b) analizar los trabajos de investigación más importantes reportados hasta la fecha sobre la morfología y estructura de los nódulos, y c) sintetizar los avances más significativos sobre la nodulación en las tres subfamilias de Fabáceas.

\section{Mecanismos de infección de los rizobios}

Los rizobios invaden las raíces de las leguminosas utilizando tres mecanismos: hilos de infección en los pelos radicales, a través de la entrada por grietas (crack entry) o a través de las células epidérmicas de la raíz (Sprent et al., 2013). El mecanismo más común, el cual fue estudiado en detalle, es a través de hilos de infección en los pelos radicales. En este caso, el intercambio de señales entre el simbionte y el huésped se inicia por la secreción de exudados de la raíz, como son los flavonoides, fenoles, azúcares, ácidos dicarboxílicos y aminoácidos. En respuesta a esa secreción, los rizobios sintetizan lipochitooligosacáridos conocidos como factores Nod. Los factores Nod desencadenan una serie de respuestas a nivel celular, entre ellas, cambios en el citoesqueleto de los pelos radicales como consecuencia de un flujo de calcio (calcium spiking). De esta forma actúan remodelando la epidermis de la planta huésped y hacen que los pelos radicales se deformen y doblen para atrapar a las bacterias dentro de ese bucle. Los rizobios atrapados se dividen y forman colonias que producen focos potenciales de infección. A partir de ahí se comienzan a formar los hilos de infección que se alargan, ramifican y penetran en el interior del nódulo emergente. La función de estas estructuras es guiar a las bacterias a través del pelo radical, atravesando de esta forma la corteza de la raíz (Oldroyd et al., 2011). Dentro del nódulo, los rizobios quedan separados del citoplasma por 
una membrana derivada de la planta hospedadora, llamada membrana peribacteroidal. Luego comienzan a dividirse de manera sincronizada y sufren profundas alteraciones morfológicas, diferenciándose en bacteroides, los cuales poseen características importantes, entre las que se destaca la expresión de la actividad nitrogenasa y de ciertos citocromos que no están presentes en las bacterias de vida libre. Estos deben adaptarse a su nuevo ambiente, de manera que se establezca una infección persistente en el nódulo y la FBN pueda ocurrir. En la subfamilia Caesalpinioideae existen casos donde no hay internalización de rizobios y la fijación de $\mathrm{N}$ se lleva a cabo en los hilos de infección (Sprent, 2008). El amonio asimilado es exportado en forma de ureídos o aminas desde los nódulos a la parte aérea a través del xilema de la planta (Oldroyd et al., 2011).

Los hilos de infección en los pelos radicales se han estudiado en detalle en leguminosas como Acacia senegal (Räsänen et al., 2001), Mimosa pudica, M. diplotricha (Chen et al., 2013) y Prosopis chilensis (Räsänen et al., 2001), pertenecientes a la subfamilia Mimosoideae; así como en Glycine max (Dupont et al., 2012), Lotus japonicum (Capoen et al., 2010; Dupont et al., 2012), Medicago sativa (Dupont et al., 2012), M. truncatula (Capoen et al., 2010) y Robinia pseudoacacia (Chen et al., 2013), todas pertenecientes a la subfamilia Papilionoideae.

En el mecanismo de crack entry los rizobios inician la infección en áreas dañadas como resultado de la aparición de raíces laterales o adventicias. La bacteria penetra a través de esas rupturas e invade los espacios intercelulares, colonizando los tejidos subepidérmicos o la corteza de la raíz. En este caso, algunas células corticales mueren por acción de los factores Nod y forman cavidades que son colonizadas por la bacteria. Estos sitios de infección parecen cumplir funciones análogas a las que se producen en los pelos radicales que sirven como origen para que los hilos de infección crezcan dentro del nódulo primordial y guíen a las bacterias (Oldroyd et al., 2011).

El mecanismo de crack entry ocurre en la especie Neptunia plena (James et al., 1992), que pertenece a la subfamilia Mimosoideae; y en leguminosas de la tribu Dalbergieae, como Adesmia bicolor (Bianco, 2014), Aeschynomene americana (Sprent et al., 2017) y Arachis hypogaea (Guinel, 2009), todas pertenecientes a la subfamilia Papilionoideae.
Los hilos de infección en los pelos radicales y el mecanismo de crack entry pueden ocurrir en la misma planta como se observó en leguminosas tropicales del género Sesbania. Este género posee aproximadamente 60 especies, de las cuales 40 se han reportado como nodulantes (Capoen et al., 2010). La especie más estudiada es Sesbania rostrata, que se encuentra naturalmente en suelos húmedos o inundados. Se considera que la nodulación es una adaptación. Puede ser nodulada por crack entry en sus raíces en condiciones de inundación y por hilos de infección en tallos y raíces bajo condiciones normales. Los rizobios que la nodulan pertenecen a los géneros Azorhizobium sp., Ensifer sp., Mesorhizobium sp. y Rhizobium sp. (Capoen et al., 2010).

Otro caso de infección simultánea es la simbiosis de Chamaecytisus proliferus y Bradyrhizobium sp., en la cual se forman hilos de infección en los pelos radicales que abortan y luego las bacterias usan el mecanismo de crack entry para completar la colonización del huésped (Vega-Hernández et al., 2001).

El tercer mecanismo conocido hasta la fecha es cuando los rizobios infectan directamente a través de la epidermis de la raíz sin formación de hilos de infección. Se observa en especies de la tribu Genisteae, como Lupinus sp., Mimosa scabrella y Retama monosperma. En el caso de M. scabrella, su raíz pierde los pelos radicales y se produce infección rizobiana a través de las células epidérmicas. Por el contrario, en otras especies de este género, la infección por rizobios ocurre de manera clásica, es decir, a través de hilos de infección (Sprent, 2005; Sprent et al., 2013).

Después que los rizobios infectan las raíces de las leguminosas comienza el proceso de organogénesis, que conduce al desarrollo del nódulo radical en el cual se alojan los rizobios que fijarán el $\mathrm{N}$ atmosférico. Este órgano vegetal se forma generalmente sobre las raíces, con algunas excepciones como en Sesbania rostrata (Sprent et al., 2017).

\section{Morfología del nódulo}

Los nódulos pueden tener diferentes formas y estructuras. Su crecimiento puede ser determinado o indeterminado. En la Tabla 1 se describen las principales diferencias, entre las cuales se encuentran el sitio donde se producen las primeras 
Tabla 1. Principales diferencias entre nódulos determinados e indeterminados.

\begin{tabular}{|c|c|c|c|c|}
\hline Nódulos & Origen & $\begin{array}{c}\text { Actividad } \\
\text { meristemática }\end{array}$ & Forma y tamaño & $\begin{array}{l}\text { Productos } \\
\text { transportados }\end{array}$ \\
\hline 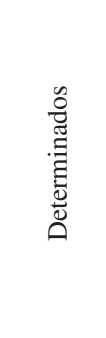 & $\begin{array}{l}\text { Las primeras divisiones celulares ocurren } \\
\text { en las células subepidérmicas de la } \\
\text { superficie de la corteza. } \\
\text { La diferenciación de las células ocurre de } \\
\text { manera sincronizada y, al cabo de cierto } \\
\text { tiempo, estas mueren. Por lo tanto, estos } \\
\text { nódulos viven unas pocas semanas. Cuando } \\
\text { entran en senescencia, se forman nódulos } \\
\text { en las partes más jóvenes de la raíz. }\end{array}$ & $\begin{array}{l}\text { Temporal. } \\
\text { Son viables durante } \\
\text { un corto período de } \\
\text { tiempo. }\end{array}$ & $\begin{array}{l}\text { Esférico. } \\
\text { El tamaño varía entre } 2 \text { y } 5 \mathrm{~mm} \\
\text { de diámetro. }\end{array}$ & Amidas \\
\hline 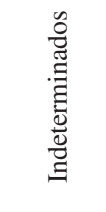 & $\begin{array}{l}\text { Las primeras divisiones ocurren en } \\
\text { el interior de la corteza, seguidas por } \\
\text { divisiones en la endodermis y el periciclo, } \\
\text { generando nuevos tejidos que son } \\
\text { infectados por los rizobios. }\end{array}$ & $\begin{array}{l}\text { Prolongada. } \\
\text { La senescencia no } \\
\text { ocurre rápidamente. }\end{array}$ & $\begin{array}{l}\text { Elongado. } \\
\text { El tamaño varía desde } 3 \mathrm{~mm} \text { a } \\
\text { varios centímetros de longitud. } \\
\text { Pueden ser no ramificados o muy } \\
\text { ramificados. }\end{array}$ & Ureidos \\
\hline
\end{tabular}

divisiones celulares, el mantenimiento del tejido meristemático, la forma del nódulo y los productos transportados (Ferguson et al., 2010; Sprent et al., 2013). Estudios recientes han propuesto otros tipos de nódulos además de los detallados anteriormente: I) nódulos determinados tipo aeschynomenoide de forma oblonga asociados con raíces laterales o adventicias, presentes en las tribus Adesmiae, Aeschynomeneae, Dalbergieae; II) nódulos determinados tipo desmoide, los cuales son esféricos, con lenticelas y están presentes en las tribus Loteae y Phaseoleae; III) nódulos indeterminados tipo lupinoide que forman un collar alrededor de la raíz presentes en Listia sp. y Lupinus sp.; IV) nódulos indeterminados no ramificados que son comunes en la subfamilia Mimosoideae; V) nódulos indeterminados con pocas ramificaciones presentes en especies de la subfamilia Papilionoideae, y VI) nódulos indeterminados con muchas ramificaciones que se encuentran en todas las subfamilias. Es imprescindible realizar una investigación exhaustiva sobre estos tipos de nódulos, ya que generalmente pertenecen a plantas que son de gran importancia para la agricultura (Sprent et al., 2017). En la Tabla 2 se muestran los distintos tipos de nódulos reportados hasta la fecha en los géneros de las tres subfamilias de Fabáceas. En la subfamilia Caesalpinoideae, los géneros pertenecientes a las tribus Caesalpinieae y Cassieae han sido los más estudiados. En cuanto a la subfamilia Mimosoideae, la investigación se ha llevado a cabo principalmente en los géneros de las tribus Ingeae y Mimoseae. Finalmente, en la subfamilia Papilionoideae, que ha sido una de las más estudiadas hasta la fecha, se destacan los géneros pertenecientes a las tribus Dalbergieae, Desmodieae, Genisteae, Loteae, Millettieae, Phaseoleae, Sophoreae y Trifolieae.

\section{Zona bacteriana por zona de infección}

Los nódulos que se forman después de la infección bacteriana consisten en una estructura que contiene regiones diferenciadas. En general están formados por tres tipos de tejidos: el tejido meristemático, el tejido vascular y el tejido parenquimático (Rothschild, 1970; Ferguson et al., 2010; Sprent et al., 2013; Sprent et al., 2017).

El tejido meristemático produce células para la formación de todos los tejidos del nódulo y para el automantenimiento de este. El tejido vascular está compuesto por haces vasculares que se ramifican y rodean la zona de infección, y que intercambian compuestos nitrogenados e irrigan al nódulo. El tejido parenquimático se diferencia en parénquima cortical y parénquima de la zona de infección ubicada en el centro del nódulo (Figuras 1 a y b). Este último puede ser uniforme (Figura 1c) o tener una mezcla de células infectadas y no infectadas (Figura 1d).

Algunas leguminosas presentan una corteza externa con signos de actividad de felógeno, cuyo resultado es la formación de la peridermis. También 
Tabla 2. Tipos de nódulos en los diferentes géneros de las tres subfamilias de Fabáceas.

\begin{tabular}{|c|c|c|c|c|}
\hline Subfamilia/ Género & Aesch. Desmoid. Det. & Indet. & Indig. Lup. & Referencia \\
\hline \multicolumn{5}{|c|}{ Caesalpinioideae } \\
\hline Campsiandra & & $\mathrm{x}$ & & Sprent, 2008 \\
\hline Chamaecrista & & $\mathrm{x}^{*}$ & & $\begin{array}{l}\text { de Faria } \text { et al., 2010; Gehlot } \text { et al., 2012; Sprent } \text { et al., 2013; } \\
\text { Sprent } \text { et al., } 2017\end{array}$ \\
\hline Dimorphandra & & $\mathrm{x}$ & & Sprent, 2008; de Faria et al., 2010; Sprent et al., 2017 \\
\hline Erythrophleum & & $\mathrm{x}$ & & Sprent, 2008 \\
\hline Melanoxylon & & $\mathrm{x}$ & & Sprent, 2008 \\
\hline Moldenhauwera & & $\mathrm{x}$ & & Sprent, 2008 \\
\hline Sclerolobium & & $\mathrm{x}$ & & Sprent, 2008 \\
\hline Tachigali & & $\mathrm{x}$ & & Sprent, 2008: de Faria et al., 2010 \\
\hline
\end{tabular}

Mimosoideae

\begin{tabular}{lll} 
Abarema & $\mathrm{x}$ & Sprent, 2005; de Faria et al., 2010 \\
Acacia & $\mathrm{x}$ & Räsänen et al., 2001; Sprent, 2005; Gehlot et al., 2012 \\
Albizia & $\mathrm{x}$ & Sprent, 2005 \\
Anadenanthera & $\mathrm{x}$ & Sprent, 2005 \\
Archidendron & $\mathrm{x}$ & Sprent, 2005; Ng y Hau, 2009 \\
Archidendropsis & $\mathrm{x}$ & Sprent, 2005 \\
Balizia & $\mathrm{x}$ & de Faria et al., 2010 \\
Calliandra & $\mathrm{x}$ & de Faria et al., 2010 \\
Chloroleucon & $\mathrm{x}$ & Sprent, 2005 \\
Cojoba & $\mathrm{x}$ & Sprent, 2005 \\
Hydrochorea & $\mathrm{x}$ & de Faria et al., 2010 \\
Desmanthus & $\mathrm{x}$ & de la Garza Requena y Valdés, 2000 \\
Elephantorrhiza & $\mathrm{x}$ & Sprent, 2005 \\
Havardia & $\mathrm{x}$ & Sprent, 2005 \\
Inga & $\mathrm{x}$ & Sprent, 2005; de Faria et al., 2010 \\
Lysiloma & $\mathrm{x}$ & Sprent 2005 \\
Macrosamanea & $\mathrm{x}$ & Sprent, 2005; de Faria et al., 2010 \\
Mimosa & $\mathrm{x}$ & Sprent, 2005; Sprent, 2008; de Faria et al., 2010 \\
Paraserianthes & $\mathrm{x}$ & Sprent, 2005 \\
Piptadeniastrum & $\mathrm{x}$ & Sprent, 2005 \\
Prosopis & $\mathrm{x}$ & Räsänen et al., 2001 \\
Stryphnodendron & $\mathrm{x}$ & de Faria et al., 2010 \\
Zygia & $\mathrm{x}$ & de Faria et al., 2010 \\
\hline & &
\end{tabular}

Papilionoideae

Abrus
Acosmium
Adesmia
Aeschynomene
Anthyllis
Astragalus
Arachis
Baphia
Brya
Centrolobium
Centrosema
Chadsia
Cymbosema
Cytisus
Dalbergia
Dalea
Dendrolobium
Desmodium
Diplotropis

$\mathrm{x}$

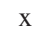

$\mathrm{X}$

$\mathrm{X}$

$\mathrm{X}$

$\mathrm{X}$

$\mathrm{X}$

$\mathrm{X}$

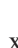

$\mathrm{X}$

$\mathrm{X}$

$\mathrm{X}$

$\mathrm{X}$
Ng \& Hau, 2009

Sprent, 2005

Lavín et al. 2001; Bianco, 2014

Sprent, 2008; Sprent et al., 2017

Ampomah et al., 2012

Ampomah et al., 2012

Sprent, 2008; Guinel, 2009

Sprent, 2005

Lavín et al. 2001; Sprent, 2005

Lavín et al. 2001; Sprent, 2005

de Faria et al., 2010

Sprent, 2005

de Faria et al., 2010

Ampomah et al. 2012

Ng y Hau, 2009; Lavín et al., 2001; Sprent, 2005

Sprent, 2005

Sprent, 2005

Ng y Hau, 2009; Sprent et al., 2017

de Faria et al., 2010 


\begin{tabular}{|c|c|c|c|c|c|c|c|}
\hline Subfamilia/ Género & Aesch. & Desmoid. & Det. & Indet. & Indig. & Lup. & Referencia \\
\hline Erythrina & & & $\mathrm{x}$ & & & & Rothschild, 1970; Sprent, 2005 \\
\hline Harpalyce & & & & $\mathrm{x}$ & & & Sprent, 2005 \\
\hline Indigofera & & & & & $\mathrm{x}$ & & Sprent et al., 2013; \\
\hline Kotschya & $\mathrm{x}$ & & & & & & Sprent, 2005 \\
\hline Flemingia & & & $\mathrm{x}$ & & & & Ng y Hau, 2009 \\
\hline Glycine & & & $\mathrm{x}$ & & & & Ferguson et al., 2010 \\
\hline Lathyrus & & & & $\mathrm{x}$ & & & Ampomah et al., 2012 \\
\hline Leptoderris & & & & $\mathrm{x}$ & & & Sprent, 2005 \\
\hline Lespedeza & & & $\mathrm{x}$ & & & & Ng y Hau, 2009 \\
\hline Lotus & & & $\mathrm{x}$ & & & & Guinel, 2009; Ferguson et al., 2010; Ampomah et al., 2012 \\
\hline Lupinus & & & & & & $\mathrm{x}$ & $\begin{array}{l}\text { Sprent, 2008; Guinel, 2009; Sprent et al., 2013; Sprent } \\
\text { et al., } 2017\end{array}$ \\
\hline Maackia & & & & $\mathrm{x}$ & & & Sprent, 2005 \\
\hline Machaerium & $\mathrm{x}$ & & & & & & Lavín et al., 2001de Faria et al., 2010 \\
\hline Melilotus & & & & $\mathrm{x}$ & & & Guinel, 2009; Ampomah et al., 2012 \\
\hline Medicago & & & & $\mathrm{x}$ & & & Guinel, 2009; Ferguson et al., 2010; Ampomah et al., 2012 \\
\hline Millettia & & & $\mathrm{x}$ & & & & Ng y Hau, 2009 \\
\hline Myrocarpus & & & $\mathrm{x}$ & & & & Rothschild, 1970 \\
\hline Ononis & & & & $\mathrm{x}$ & & & Ampomah et al., 2012 \\
\hline Ormosia & & & & $\mathrm{x}$ & & & Sprent, 2005; Ng y Hau, 2009 \\
\hline Oxytropis & & & & $\mathrm{x}$ & & & Ampomah et al., 2012 \\
\hline Phaseolus & & $\mathrm{x}$ & & & & & $\begin{array}{l}\text { Rothschild, 1970; Sprent, 2008; Guinel, 2009; Ferguson } \\
\text { et al., } 2010\end{array}$ \\
\hline Phyllodium & & & $\mathrm{x}$ & & & & $\mathrm{Ng}$ y Hau, 2009 \\
\hline Pisum & & & & $\mathrm{x}$ & & & Ferguson et al., 2010 \\
\hline Pericopsis & & & & $\mathrm{x}$ & & & Sprent, 2005 \\
\hline Platymiscium & $\mathrm{x}$ & & & & & & Lavín et al., 2001; Sprent, 2005 \\
\hline Poecilanthe & & & & $\mathrm{x}$ & & & de Faria et al., 2010 \\
\hline Pongamia & & & $\mathrm{x}$ & & & & Ferguson et al., 2010 \\
\hline Pterocarpus & $\mathrm{x}$ & & & & & & Lavín et al., 2001; Sprent, 2005 \\
\hline Rhynchosia & & & $\mathrm{x}$ & & & & Ng y Hau, 2009; Gehlot et al., 2012 \\
\hline Robinia & & & & $\mathrm{x}$ & & & Chen et al., 2013 \\
\hline Sophora & & & & $\mathrm{x}$ & & & Sprent, 2005 \\
\hline Swartzia & & & & $\mathrm{x}$ & & & Sprent, 2005; de Faria et al., 2010 \\
\hline Tadehagi & & & $\mathrm{x}$ & & & & Ng y Hau, 2009 \\
\hline Tephrosia & & & & $\mathrm{x}$ & & & de Faria et al., 2010 \\
\hline Tetragonolobus & & $\mathrm{x}$ & & & & & Guinel, 2009 \\
\hline Tipuana & $\mathrm{x}$ & & & & & & Lavín et al., 2001; Sprent, 2005 \\
\hline Trifolium & & & & $\mathrm{x}$ & & & Guinel, 2009; Ferguson et al., 2010; Ampomah et al., 2012 \\
\hline Ulex & & & & $\mathrm{x}$ & & & Ampomah et al., 2012 \\
\hline Vicia & & & & $\mathrm{x}$ & & & Guinel, 2009; Ampomah et al., 2012 \\
\hline Vigna & & $\mathrm{x}$ & & & & & Guinel, 2009 \\
\hline
\end{tabular}

Abreviaturas: Tipo de nódulos: Aesch. = aeschynomenoide; Desmoid. = desmoide; Det. = determinado; Indet. = indeterminado; Indig. $=$ indigoferoide; Lup. = lupinoide.

se ha encontrado que las especies expuestas a períodos prolongados de sequía, como Rhynchosia aurea, Tephrosia leptostachya y Vachellia jacquemontii, poseen en su peridermis capas de suber o corcho y células que contienen sustancias fenólicas y taninos. Estas adaptaciones morfológicas y estructurales en los nódulos ayudan a retener la humedad y, por lo tanto, evitan la deshidratación. En especies como Indigofera linifolia que habitan en ambientes inundados los nódulos también muestran signos de adaptación, como la presencia de lenticelas (Gehlot et al., 2012).

\section{Estudio de nodulación en las tres subfamilias de Fabáceas}

En esta última década, el análisis de los caracteres moleculares y morfológicos de la nodulación ha llevado a cambios importantes en la taxonomía en las leguminosas. Además 

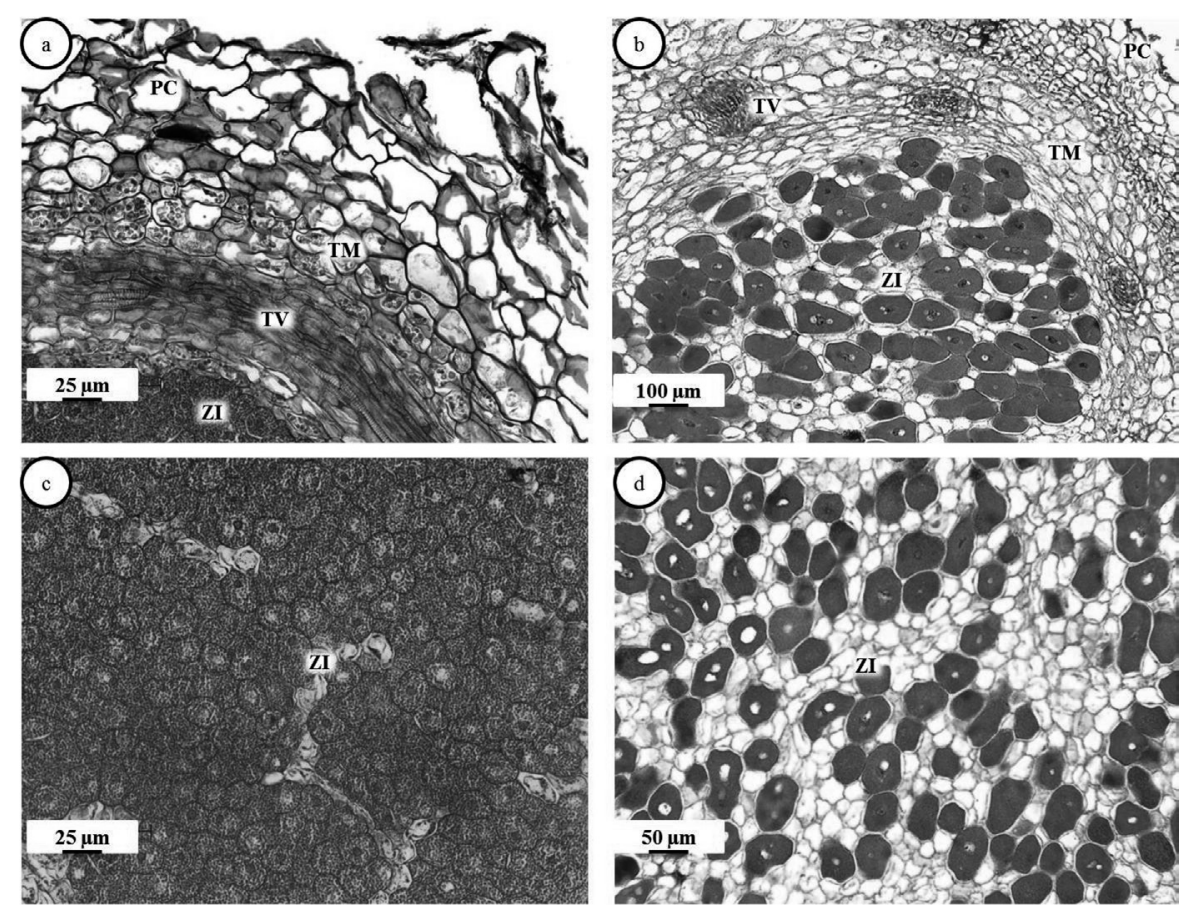

Figura 1. Cortes transversales de nódulos mostrando la estructura interna. (a y c): Adesmia bicolor, (b y d): Robinia pseudoacacia.

Abreviaturas: $\mathrm{PC}:=$ Parénquima cortical, $\mathrm{TM}=$ Tejido meristemático, $\mathrm{TV}=$ Tejido vascular. $\mathrm{ZI}:=$ Zona de infección. Las barras de escala $=25 \mu \mathrm{m}, 50 \mu \mathrm{m}$ y $100 \mu \mathrm{m}$.

se han incrementado notablemente los estudios de los géneros y las especies de rizobios que las nodulan (Sprent et al., 2017). Aunque la literatura en nodulación y FBN en leguminosas nativas que crecen en diferentes partes del mundo es abundante (Sprent et al., 2013), se sabe poco hasta la fecha sobre la capacidad de varias especies para formar nódulos y fijar $\mathrm{N}$ en su ecosistema natural. Solo el $20 \%$ de las leguminosas nativas que pertenecen a las tres subfamilias de las Fabáceas se han estudiado en detalle. Los resultados de estos estudios confirmaron que la nodulación es más frecuente en las subfamilias de Mimosoideae y Papilionoideae en comparación con Caesapinioideae, en cuyo caso solo se ha examinado el $23 \%$ de sus especies (Sprent, 2007).

En la subfamilia Caesalpinioideae la mayoría de los géneros (171 géneros y 2.250 especies) incluyen árboles ampliamente distribuidos en los trópicos húmedos y a menudo en los mismos hábitats que aquellos donde crecen especies noduladas de las otras subfamilias. Los nódulos en general tienen un crecimiento indeterminado con ramificaciones. En algunas especies del género Chamaecrista
(Tabla II*) los nódulos se consideran del tipo primitivo, ya que tienen bacteroides retenidos dentro de los hilos de infección durante todo el período de FBN. En este caso las bacterias son rechazadas porque la planta no las reconoce como beneficiosas (Sprent, 2007; Sprent et al., 2013). Dentro de esta sub-familia existen especies como Campsiandra laurifolia, Erythrophleum suaveolens y Melanoxylon brauna que se consideran importantes para la construcción, producción de taninos, producción de carbón y usos medicinales (Sprent y Parsons, 2000).

Con respecto a la subfamilia Mimosoideae (78 géneros y 3.270 especies), incluye árboles y arbustos que crecen no solo en zonas tropicales y subtropicales, sino también en zonas secas. Se ha informado que varios géneros de esta subfamilia poseen capacidad para nodular (Tabla II). Los nódulos son de crecimiento indeterminado con diversos grados de ramificación e infección a través de los pelos radicales (Sprent et al., 2013; Sprent et al., 2017). Especies de esta subfamilia como Acacia Senegal, Albizia lebbeck, Anadenanthera colubrina y Enterolobium cyclocarpum son 
utilizadas para la construcción, producción de madera, forraje, drogas alucinógenas y plantas de sombra para otros cultivos (Sprent y Parsons, 2000). Dentro del género Prosopis hay especies que son importantes por su tolerancia a la sequía y a la sal, por lo cual son utilizadas para la recuperación de tierras. También se destacan comercialmente porque producen madera, miel, medicinas y taninos, y son utilizadas como forraje (Sprent, 2005).

Finalmente, la subfamilia Papilionoideae (764 géneros y 13.800 especies) es una de las más estudiadas. Se caracteriza por presentar árboles, arbustos pequeños y hierbas anuales o perennes con una distribución cosmopolita que se extiende desde los trópicos hasta el ártico. Investigaciones previas (Sprent, 2007; Sprent et al., 2013; Sprent et al., 2017) han confirmado que la nodulación ocurre en la mayoría de sus géneros (Tabla II), lo que ha evidenciado diferentes mecanismos de infección bacteriana y estructura de nódulos. Dentro de esta subfamilia se destacan especies como Andira inermis, Hymenolobium excelsum, Robinia pseudoacacia, Swartzia madagascariensis y Xanthocercis madagascariensis, que son importantes porque producen madera, carbón, taninos, drogas medicinales y frutos comestibles. Robinia pseudoacacia también es utilizada para la rehabilitación de tierras (Sprent y Parsons, 2000). Algunas especies dentro de esta subfamilia también tienen importancia a nivel agronómico, como Arachis hypogaea (Guinel, 2009) y Glycine max (Dupont et al., 2012).

\section{Conclusiones}

En las leguminosas de las tres subfamilias de Fabáceas, los rizobios invaden las raíces a través de tres mecanismos: hilos de infección en los pelos radicales, crack entry o a través de las células epidérmicas de la raíz. Como resultado de la infección bacteriana se forman distintos tipos morfológicos de nódulos. Con respecto a la estructura de los nódulos, se ha demostrado que están formados por tres tipos de tejidos: el meristemático, el vascular y el parenquimático. Cada tejido cumple una función específica en la formación y desarrollo del nódulo y en el proceso de FBN. En especies sujetas a condiciones ambientales como sequía o inundación, se observan algunas modificaciones en la estructura interna, como la formación de peridermis y lenticelas. Actualmente la subfamilia Papilionoideae es la más estudiada en cuanto a nodulación, particularmente los géneros pertenecientes a las tribus Dalbergieae, Desmodieae, Genisteae, Loteae, Millettieae, Phaseoleae, Sophoreae y Trifolieae.

Debido a su importancia a nivel económico y ecológico sería conveniente continuar con los estudios para identificar especies de leguminosas nativas que presenten alta capacidad para la nodulación y FBN, a fin de aplicar estrategias de manejo y conservación, y prevenir el avance de la desertificación en regiones áridas.

\section{Literatura Citada}

Ampomah, O.Y.; James E.K.; Iannetta P.P.M.; Kenicer G.; Sprent J.I.; Huss-Dannel K.

2012. Nodulation and ecological significance of indigenous legumes in Scotland and in Sweden. Symbiosis, 57: 133-148.

Bianco, L.

2014. Rhizobial infection in Adesmia bicolor (Fabaceae) roots. Archives of Microbioly, 196: 675-679.

Capoen, W.; Goormachtig, S.; Holsters, M.

2010. Water-tolerant legume nodulation. Journal of Experimental Botany, 61: 1251-1255.

Chen, H.; Chou, M.; Wang, X.; Liu, S.; Zhang, F.; Wei, G.

2013. Profiling of differentially expressed genes in roots of Robinia pseudoacacia during nodule development using suppressive subtractive hybridization. PLoS One, 8: 63930.

de Faria, S.M.: Diedhiou A.G.; de Lima H.C.; Ribeiro R.D.; Galiana A.; Castilho A.F.; Henriques J.C.

2010. Evaluating the nodulation status of leguminous species from the Amazonian forest of Brazil. Journal of Experimental Botany, 61: 3119-3127. de la Garza Requena, F.; Valdés M.

2000. Tamaño de la población microbiana del suelo y desarrollo inicial de Desmanthus virgatus (1.) willd. Agrociencia, 34: 445-451.

Dupont, L.; Alloing G.; Pierre O.; Msehli S.E.L.; Hopkins J.; Hérouart D.; Frendo P.

2012. The Legume Root Nodule: From Symbiotic Nitrogen Fixation to Senescence. In: Nagata, T. (ed.). Senescence. In Tech. pp. 138-156.

Ferguson, B.J., Indrasumunar, A., Hayashi S.; Lin M.H.; Lin Y.H.; Reid D.E.; Gresshoff P.M.

2010. Molecular analysis of legume nodule development and autoregulation. Journal of Integrative. Plant Biology, 52: 61-76.

Gehlot, H.S.; Panwar, D.; Tak, N.; Tak, A.; Sankhla, I.S.; Poonar, N.; Parihar, R.; Shekhawat, N.S.; Kumar, M.; Tiwari, R.; Ardley, J.; James, E.K.; Sprent J.I.

2012. Nodulation of legumes from the Thar desert of India and molecular characterization of their rhizobia. Plant Soil, 357: 227-243. 
Guinel, F.C.

2009. Getting around the legume nodule: I. The structure of the peripheral zone in four nodule types. Botany, 87: 1117-1138.

James, E.K.; Sprent, J.I.; Sutherland, J.M.; Mcinroy, S.G.; Minchin, F.R.

1992. The structure of nitrogen fixing root nodules on the aquatic mimosoid legume Neptunia plena. Annals of Botany, 69: 173-180.

Ng, A.Y.S.; Hau B.C.H.

2009. Nodulation of native woody legumes in Hong Kong. Plant and Soil, 316: 35-43.

Oldroyd, G.E.D.; Murray, J.D.; Poole, P.S.; Downie, J.A.

2011.The rules of engagement in the legume-rhizobial symbiosis. Annual Review of Genetics, 45: 119-44.

Räsänen, L.A.; Sprent, J.I.; Lindström, K.

2001. Symbiotic properties of Sinorhizobia isolated from Acacia and Prosopis nodules in Sudan and Senegal. Plant and Soil, 235: 193-210.

Rothschild, D.I.

1970. Anatomía nodular en especies de leguminosas del norte argentino. VI Reunión Latinoamericana sobre Rhizobium. Pp. 54-61.

Schimel, D.S.

2010. Dry lands in the earth system. Science, 327: 418-419.

Sprent, J.I.; Parsons. R.

2000. Nitrogen fixation in legume and non-legume trees. Field Crops Research, 65: 183-196.
Sprent, J.I.

2005. Nodulated legume trees. In: Werner, D.; Newton, W.E. (Eds.). Nitrogen fixation in agriculture, forestry, ecology, and the environment. Springer, Dordrecht. pp. 113-141.

Sprent, J.I.

2008. Evolution and diversity of legume symbioses. In: Dilworth, M.J.;James, E.K.; Sprent, J.I.; Newton, E.E. (eds.). Nitrogen-fixing leguminous symbioses. Dordrecht, the Netherlands: Springer 7: 1-21.

Sprent, J.I.; Gehlot H.S.

2010. Nodulated legumes in arid and semi-arid environments: are they important? Plant Ecology and Diversity, 3: 211-219.

Sprent, J.I.; Ardley, J.K.; James, E.K.

2013. From North to South: A latitudinal look at legume nodulation processes. South African Journal of Botany, 89: 31-41.

Sprent, J.I.; Ardley J.; James E.K.

2017. Biogeography of nodulated legumes and their nitrogenfixing symbionts. New Phytologist, 215: 40-56.

Vega-Hernández, M.C.; Pérez-Galdona, R.; Dazzo, F.B.; JaraboLorenzo, A.; Alfayate, M.C.; León-Barrios, M.

2001. Novel infection process in the indeterminate root nodule symbiosis between Chamaecytisu sproliferus (tagasaste) and Bradyrhizobium sp. New Phytologist, 150: 707-721.

Zahran, H.H.

1999. Rhizobium - legume symbiosis and nitrogen fixation under severe conditions and in an arid climate. Microbiology and Molecular Biology Reviews, 63: 968-989. 
